\title{
Performance evaluation of paper embossing tools produced by fused deposition modelling additive manufacturing technology
}

\begin{abstract}
From its beginnings, up to a few years ago, additive manufacturing technology was able to produce models or prototypes which have limited use, because of materials mechanical properties. With advancement and invention of new materials, this is changing. Now, it is possible to create $3 D$ prints that can be used as final products or functional tools, using technology and materials with low environmental impact. The goal of this study was to examine opportunities for production of paper embossing tools by fused deposition modelling (FDM) 3D printing. This study emphasises the use of environmentally friendly poly-lactic acid (PLA) materials in FDM technology, contrary to the conventional method using metal alloys and acids. Embossing of line elements and letters using 3D printed embossing tools was done on six different types of paper. Embossing force was applied using SHIMADZU EZ-LX Compact Tabletop Testing Machine. Each type of paper was repeatedly embossed using different values of embossing force (in $250 \mathrm{~N}$ increments, starting at $1000 \mathrm{~N}$ ) to determine the optimal embossing force for each specific paper type. When determined, the optimal embossing force was used on ten samples for each paper type. Results of embossing were analysed and evaluated. The analysis consisted of investigating the effects of the applied embossing force and characteristics such as paper basis weight, paper structure, surface characteristic and fibre direction of the paper. Results show that paper characteristics determine the embossing force required for achieving a good embossing result. This means that with the right amount of embossing force, letters and borderlines can be equally well formed by the embossing process regardless of paper weight, surface characteristics, etc. Embossing tools produced in this manner can be used in case of the embossing elements that are not complex. The reason for this is the limitation of FDM technology and lack of precision needed for fine details. However, if the form is simple enough, results of pleasing quality can easily be achieved.
\end{abstract}

\section{KEY WORDS}

FDM technology, PLA, embossing tool

\section{Introduction}

\section{Rapid manufacturing, rapid tooling and fused deposition modelling}

In contrast to many manufacturing processes defined as subtractive, where the process starts with a mass

\author{
Gordana Delić, \\ Gojko Vladić, \\ Magdolna Pál, \\ Bojan Banjanin, \\ Sandra Dedijer
}

University of Novi Sad, Faculty of Technical Sciences, Department of Graphic Engineering and Design, Novi Sad, Serbia

\section{Corresponding author: Gordana Delić e-mail: gordana.delic@uns.ac.rs}

First recieved: 06.11.2017. Accepted: 19.12.2017. 
(3DP), selective laser sintering (SLS), fused deposition modelling (FDM) etc. Every AM process typically starts with a 3D CAD model, exported as an STL file that a software controlling 3D printing machine can interpret and prepare for printing. In the FDM process the printed object is build up from a filament of material extruded out of a fine nozzle and deposited on the platform (Upcraft \& Fletcher, 2003). The head of the nozzle is moved in both horizontal $x$-axis and $y$-axis, while the build platform moves up or down (z-axis). The control of this mechanism is carried out using a computer-aided manufacturing (CAM) software tool which runs a microcontroller (Izdebeska \& Thomas, 2015). As the thin-cross selection slice is printed, the platform lowers relative to the nozzle, and next slice is deposited on the top of the first. The process repeats until the model is finished. Since the deposited filaments are hot, layers bound and while cooling, they form a firm structure. The big advantage of the FDM process is the variety of filament materials which can be used, affordable price and opportunity of utilisation in an office environment (Upcraft \& Fletcher, 2003). Various polymers can be used as a building material, including acrylonitrile butadiene styrene (ABS), polycarbonate (PC), poly-lactic acid (PLA), high-density polyethene (HDPE), PC/ABS, polyphenyl-sulfone (PPSU), and high-impact polystyrene (HIPS). The polymer can be in the form of a filament fabricated from virgin polymers, but also there is a resurgence in converting post-processed consumer plastic waste into filament (Izdebeska \& Thomas, 2015). Today there is a high demand for rapid tooling (RT) technologies to support product development by fast manufacturing of tooling and tooling inserts which allow the production of larger series. RT aims to produce long-term consistency tools or a tool that can form several thousand or even millions of parts before it wears out (Levy, Schindel \& Kruth, 2003). FDM technology has the potential of producing jigs, fixtures, tool masters and even production tooling in low-volume in-house that can be done in hours or days (Stratasys, 2015). The disadvantage of FDM technology is related to the precision of printing, which is conditioned by the elliptical or circular filament cross-section. These circular cross-sections of filaments prevent the production of ideal right angles (Upcraft \& Fletcher, 2003).

\section{Embossing}

Embossing is a forming process where the surface of a substrate is changed under the influence of high embossing force (Tschaetsch \& Koth, 2006). Embossing produces an image raised above or sunken below (also known as debossing) the surface of the paper and gives the paper the third dimension. A type of embossing, where every part of a design, that is being embossed, is also being foiled, is referred to as foil embossing. If embossing does not include the use of ink or foil to highlight the embossed area, it is called blind embossing. Blind embossing provides a clean and subtle image on the paper surface due to the shadows (Haslam, 2006). When embossing/debossing is performed, an embossing tool must be fabricated. An embossing tool consists of one component thus achieving one-sided impressions; a process called stamping. Also, there are embossing tools consisting of two components which are investigated in this research. Two components of the embossing tool are the female (negative) die, which has recessed embossing elements and the counter male (positive) die which has raised embossing elements. The substrate is pressed between these two parts leaving an impression on its surface (Gonnella \& Navetta, 2010). The depth and width of the female die element are larger than the convex male die element by the thickness of the substrate (Tschaetsch \& Koth, 2006). The production of image elements on embossing die-form is usually done by etching with acid (Haslam, 2006). Dies can be made out of magnesium, copper, brass or metal alloys (Ryan, Conover \& Conover, 2004). The goal of this study was to investigate the usability of FDM technology in creating embossing tools. The study emphasises the use of environmentally friendly poly-lactic acid (PLA) materials in FDM technology over the conventional acid-etched processes using metal alloys and acids.

\section{Methodology}

\section{Materials}

Poly-lactic acid (PLA)

In this research, PLA filament was used as a building material. PLA is linear aliphatic thermoplastic polyester, produced from renewable and biodegradable resources as an alternative to conventional polymers, such as polyethene (PE), polypropylene (PP), polyethene terephthalate (PET), etc. PLA is produced by ring-opening polymerisation of lactide, and the lactic acid monomers are obtained from the fermentation of sugar feedstocks (Carrasco et al., 2010). Production of lactic acid is done at a low price due to fermentation of D-glucose from corn and other biomass substrates. PLA has numerous qualities such as good mechanical properties, processability and low environmental impact. Specifications of PLA materials are shown in Table 1 (Carrasco et al., 2010). With PLA it is possible to print detailed objects at relatively high speeds (Nicklievendag, 2016). It doesn't have any heavy metals, phthalates, or BPA (Bisphenol A) (Makerbot, 2016).

\section{Paper}

For this investigation, four different paper types have been selected for embossing. Specifications of each type are shown in Table 2. 


\section{Table 1}

Specification of PLA filaments used in FDM 3D printing technology (Carrasco et al., 2010)

\begin{tabular}{|c|c|}
\hline Property of PLA & Value \\
\hline Relative density & 1.24 \\
\hline Clarity & Transparent \\
\hline \multicolumn{2}{|l|}{ MECHANICAL PROPERTIES } \\
\hline Tensile yield strength [MPa] & $48-110$ \\
\hline Tensile modulus [GPa] & $3.5-3.8$ \\
\hline Tensile elongation [\%] & 2.5- 100 \\
\hline Notched Izod impact, $23^{\circ} \mathrm{C}[\mathrm{J} / \mathrm{m}]$ & 13 \\
\hline \multicolumn{2}{|l|}{$\begin{array}{l}\text { THERMAL PROPERTIES OF } \\
\text { PLA FILAMENT [Makerbot, 2016] }\end{array}$} \\
\hline Glass transition temperature $\left[{ }^{\circ} \mathrm{C}\right]$ & $60-65$ \\
\hline Melting temperature $\left[{ }^{\circ} \mathrm{C}\right]$ & $150-160$ \\
\hline Vicat temperature $\left[{ }^{\circ} \mathrm{C}\right]$ & $55-60$ \\
\hline Nozzle temperature $\left[{ }^{\circ} \mathrm{C}\right]$ & 230 \\
\hline \multicolumn{2}{|l|}{ DIMENSION PROPERTY } \\
\hline Filament Diameter [mm] & 1.75 \\
\hline
\end{tabular}

\section{Procedure}

The first step in the experiment was the creation of the 3D model using Dassault Systemes CATIA, the CAD software. Embossing tool consists of two dies: one that is raised and one that is recessed. The dies fit into each other so that the paper can be pressed between them; the dimensions of the dies are $60 \mathrm{~mm} \times 60 \mathrm{~mm}$. The die with raised elements is $3 \mathrm{~mm}$ thick and the opposite recessed die is $2 \mathrm{~mm}$ thick. The male die has raised letters " $G, R, I, D$ " and borders made of lines that separate them. These same elements are recessed on the second (female) die. The height and depth of raised and recessed elements are $1 \mathrm{~mm}$. To avoid damaging the edges of the embossed elements, on the paper, chamfer of $30^{\circ}$ was created on the embossing tool edges. Figure 1 shows a $3 \mathrm{D}$ model of the embossing tool created using CATIA CAD software. The 3D CAD file was exported as a STL file and translated into instructions for the Maker Bot Replicator $5^{\text {th }}$ generation 3D printer using MakerBot Desktop. The printing process parameters are shown in Table 3.

\section{Table 3}

Print settings in MakerBot software

\begin{tabular}{l|l}
\hline Property & Value \\
\hline Infill $[\%]$ & 100 \\
\hline Extruder temperature $\left[^{\circ}\right]$ & 150 \\
\hline Print speed $[\mathrm{mm} / \mathrm{s}]$ & 90 \\
\hline Layer height $[\mathrm{mm}]$ & 0,1 \\
\hline Number of shells & 2 \\
\hline Extruder type & Smart extruder \\
\hline Build material & Maker Bot PLA \\
\hline Support structure & No \\
\hline Printing duration $[\mathrm{min}]$ & 126 \\
\hline
\end{tabular}

Table 2

Specifications of selected paper samples (Sappy, 2016)

\begin{tabular}{l|l|l|l}
\hline Mark & Type of the paper & $\begin{array}{l}\text { Basis weight } \\
{\left[\mathbf{g} / \mathbf{m}^{2}\right]}\end{array}$ & $\begin{array}{l}\text { Thickness } \\
{[\boldsymbol{\mu m}]}\end{array}$ \\
\hline OF80 & $\begin{array}{l}\text { woodfree uncoated } \\
\text { offset (Sappi Tauro) }\end{array}$ & 80 & 103 \\
\hline OF140 & $\begin{array}{l}\text { woodfree uncoated } \\
\text { offset (Sappi Tauro) }\end{array}$ & 140 & 168 \\
\hline V080 & $\begin{array}{l}\text { bulky, wood fibre paper } \\
\text { (Munken Pocket } \\
\text { Cream, voluminous) }\end{array}$ & 80 & 136 \\
\hline MC90 & $\begin{array}{l}\text { matt coated } \\
\text { (Sappi Quatro Gloss, matt) }\end{array}$ & 90 & 64 \\
\hline MC130 & $\begin{array}{l}\text { matt coated } \\
\text { (Sappi Quatro Gloss, matt) }\end{array}$ & 130 & 94 \\
\hline GC130 & $\begin{array}{l}\text { glossy coated } \\
\text { (Sappi Quatro Silk, glossy) }\end{array}$ & 130 & 108 \\
\hline
\end{tabular}
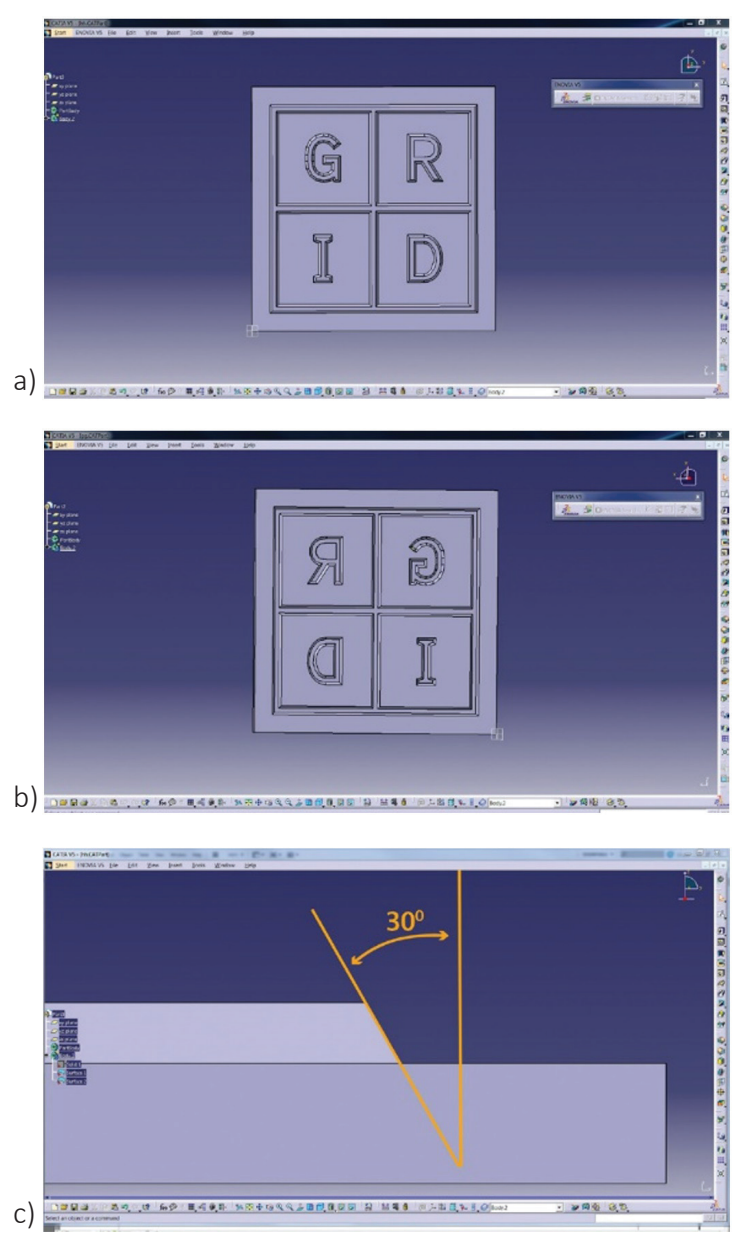

» Figure 1: CATIA model of the embossing tool a) male die b) female die c) chamfering the edge of embossing elements of $30^{\circ}$ 
After the printing, the model was separated from the raft, and it was ready to be used as an embossing tool. Figure 2 shows the embossing tool during the printing process (a) and finished 3D embossing tool (b).

a)
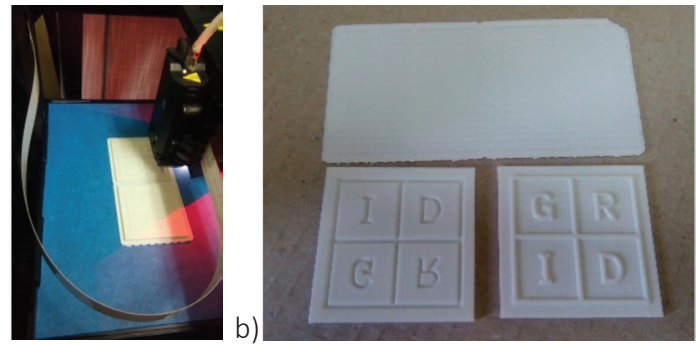

» Figure 2: a) 3D printed embossing tool while printing b) finished embossing tool

The embossing process with a range of embossing forces was done using SHIMADZU Compact Tabletop Testing Machine EZ-LX. Fixed compression plates (radius $118 \mathrm{~mm}$ ) and 2,5 kN load cell were mounted to precisely determine the embossing force.

Embossing was tested on six paper types (OF80, OF140, MC90, MC130, GC130 and VO80). Each type of paper was tested using different values of embossing forces until the optimal force for each type was determined (starting with $1000 \mathrm{~N}$, up to $1500 \mathrm{~N}$ ). Optimal embossing force should ensure clear impression without damage to the sample. The optimal force was then applied to ten samples for every type of paper. Within those ten samples, five had their fibre direction positioned perpendicular, and five had their fibre direction positioned parallel to the letter orientation. For determining the optimal embossing force, the quality of impression and tearing or puncture of the paper were taken into consideration. Lack of relief and bad visibility of embossed elements suggest that insufficient embossing force was applied, while if embossed elements tear or puncture the paper's surface the embossing force was excessive.

In the second stage, the influence of paper characteristics on embossing results was analysed. Examined characteristics were paper basis weight, paper structure, surface characteristic and fibre direction. The embossed paper samples were scanned using Canon CanoScan $5600 \mathrm{~F}$ at 1200 spi, RGB colour space as a JPG output file for archiving and subsequent image analysis. Samples were being rotated four times by $90^{\circ}$ to minimise the influence of the self-shadowing on the samples.

The analysis was performed by visual assessment. To achieve the correct visual assessment, the brightness values of pixels in images were redistributed using equalise filter in Adobe Photoshop CS6, so that they more evenly represent the entire range of brightness levels. The green channel was isolated, and the images were converted to grayscale.

\section{Results and Discussions}

\section{Defining the optimal embossing force for each paper type}

Using the method explained earlier, optimal embossing forces were selected for all of the tested paper samples. The applied lowest embossing force of $1000 \mathrm{~N}$ was sufficient for achieving adequate visibility without any surface damage to the samples with lower basis weight (OF80 and MC90), excepting the bulky/voluminous paper (VO80). For that sample, embossing force of $1000 \mathrm{~N}$ was insufficient, and the next predefined value of $1250 \mathrm{~N}$ created damages to the sample. Because of this, the sample was tested with the value of $1100 \mathrm{~N}$, which turned out to be the optimal embossing force. Embossing force of $1250 \mathrm{~N}$ was required for the matt coated sample, MC130 and embossing force of $1500 \mathrm{~N}$ was needed for the glossy coated sample, GC 130, whereas the highest embossing force of $1750 \mathrm{~N}$ was required for the offset paper sample, OF140. Values of optimal embossing forces applied for each paper type are presented in Figure 3.

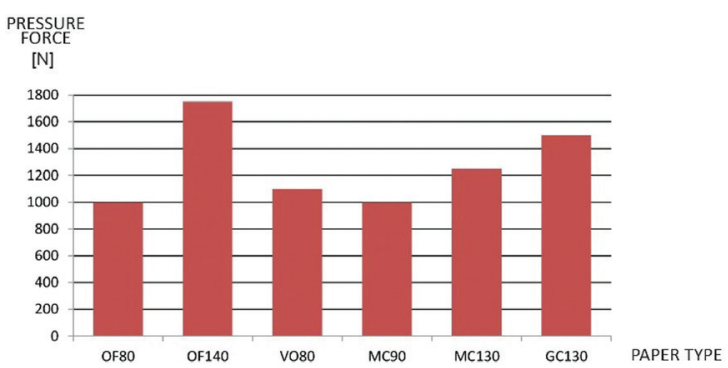

» Figure 3: Optimal embossing forces for each paper type

\section{Influence of the paper's basis weight on embossing parameters and results}

In this analysis, the influence of the basis weight difference amongst papers on the embossing results was examined. The comparison was made between the two uncoated offset paper samples, OF80 (Figure 4a) and OF140 (Figure 4b) and between the two matt coated samples, MC90 (Figure 5a) MC130 (Figure 5b). As it is easy to see on the displayed images, letters and borderlines are well defined, regardless of the basis weight in both types of paper (uncoated and coated). It can be noted that the characteristic phenomenon of mild pucker of paper on the outside corners of the borderlines at lower basis weight is probably due to lower paper thickness.

\section{Influence of structure of paper on embossing parameters and results}

In this analysis, the influence of different paper structure on the embossing results obtained using tools produced by FDM technology was examined. The type 
a)

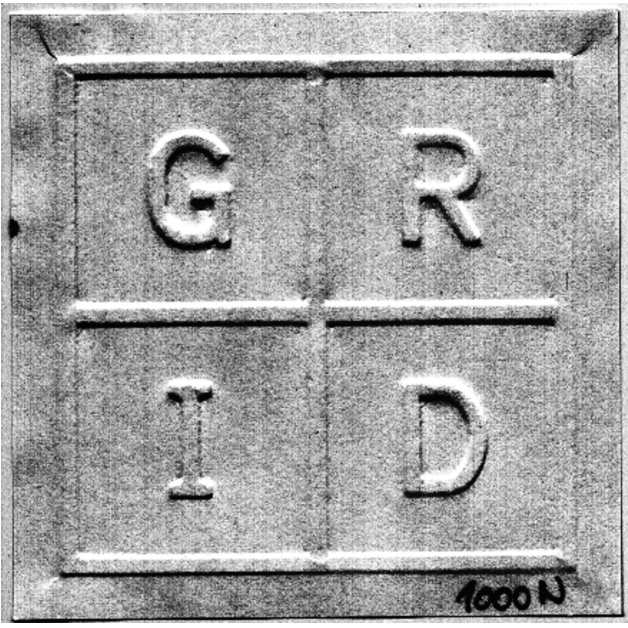

b)

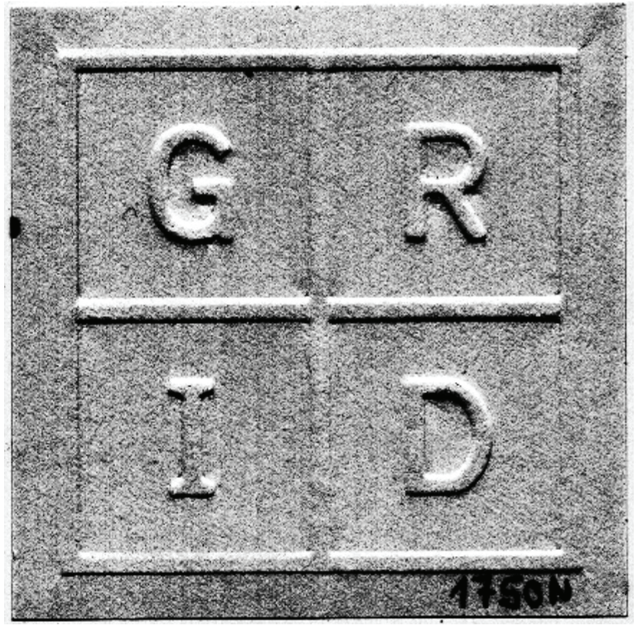

» Figure 4: Appearance of embossed surface on a) OF80 and b) OF140 paper

a)

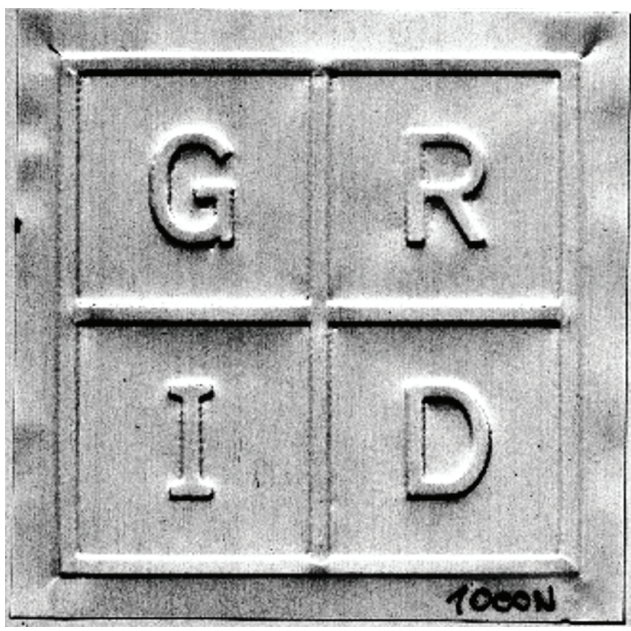

b)

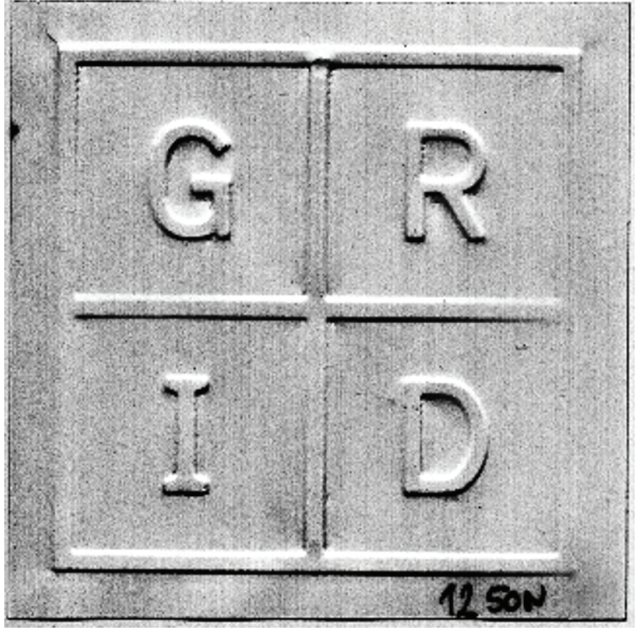

» Figure 5: Appearance of embossed surface on a) MC9O and b) MC130 paper
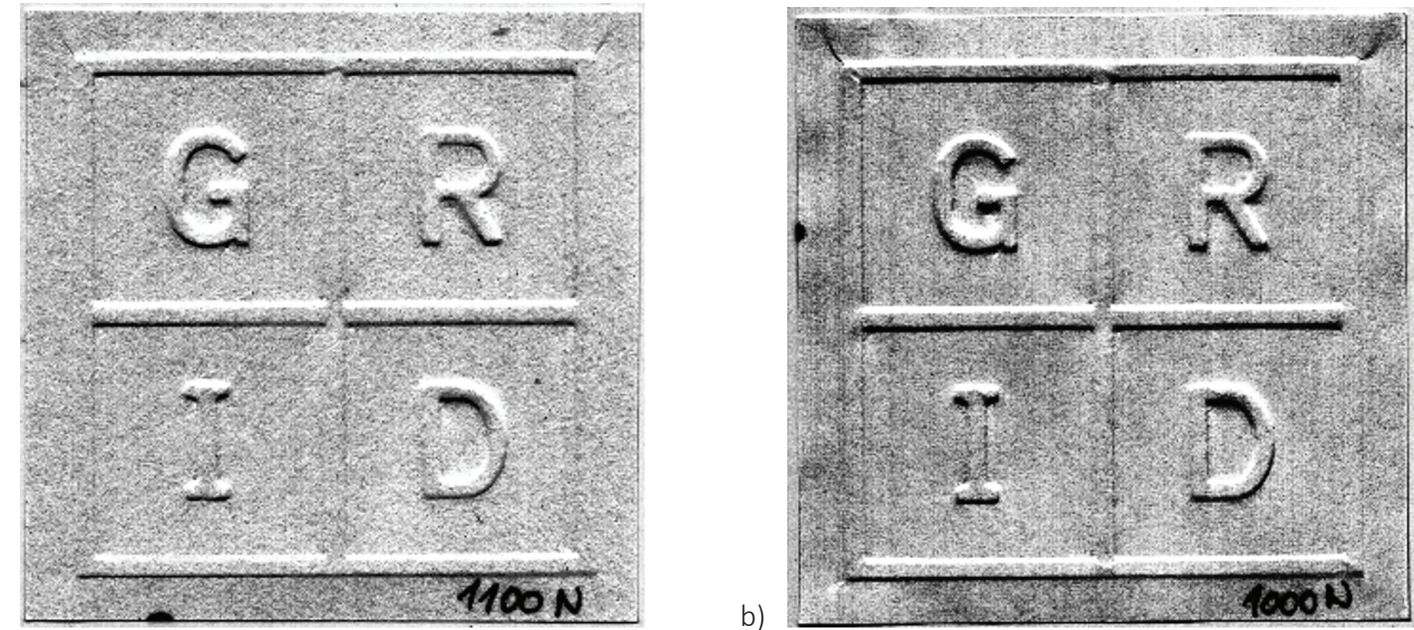

» Figure 6: Appearance of embossed surface on a) VO80 and b) OF80 paper

of the paper with the same basis weight was tested, but it differs in filler and fibre content. The comparison was made between VO80 (Figure 6a) and OF80 (Figure 6b). The voluminous paper is medium fine with reduced filler content, and an offset paper is wood free with up to $15 \%$ of fillers in its composition. Letters are equally well-formed, as well as borderlines. As it can be seen from the Figure 6, the uncoated offset paper has more apparent puckers 
in the corners then voluminous paper. This is due to the greater thickness of voluminous paper for the same basis weight. According to filler and fibre content, the surface of voluminous paper visually seems to be rougher compared to the uncoated offset paper. Based on these results, it can be assumed that the embossing tool with a smaller gap would give better results in embossing of the uncoated offset paper, due to its lower thickness.

\section{Influence of surface characteristics on embossing parameters and results}

The influence of the difference in surface characteristics of the paper on embossing results was analysed. The comparison was made between the uncoated offset papers, (OF80, Figure 7a and OF140, Figure 8a) and matt coated papers (MC90, Figure 7b, MC 130, Figure 8b). Results show that equal amount of embossing force is required for achieving optimal embossing results either for MC90 or OF80. In comparison between MC130 and OF140, results show that OF140 needs a

a)

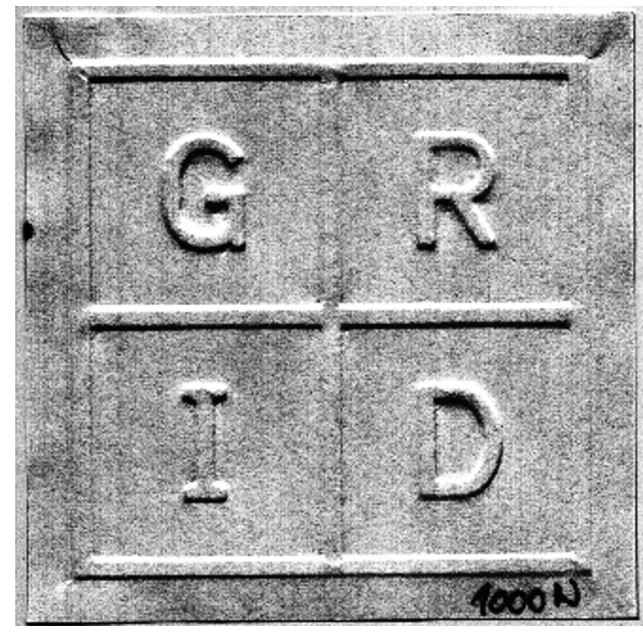

higher embossing force. Different embossing forces at higher paper basis weights indicate that between them there is a greater difference in the total amount of pigment (fillings and coatings). Embossing force needs to overcome the elasticity of the fibre and cause a plastic deformation in them. If there was more fibre in the paper, a greater embossing force was required.

\section{Influence of fibre direction on embossing parameters and results}

In this analysis, the influence of the fibre direction on embossing results was examined. The comparison was done within the one type of paper, but with different fibre directions. Parallel to the fibre direction, paper samples exhibit higher elongation with less resistance while embossing. Therefore damages were occurring mostly perpendicular to the fibre direction in the form of crack lines. Examples of that kind of surface destruction can be seen on the MC90 sample in Figure 9 and 10. Having this in mind, applying certain adjustments

» Figure 7: Appearance of embossed surface on a) OF80 and b) MC9O paper

a)

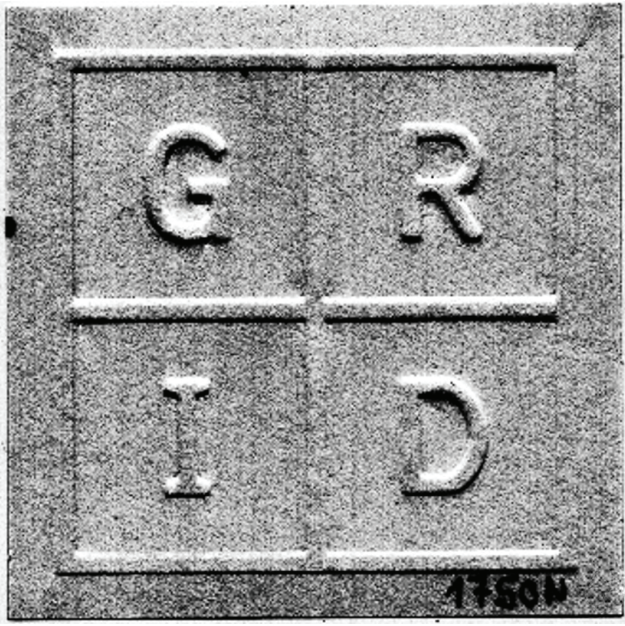

b)

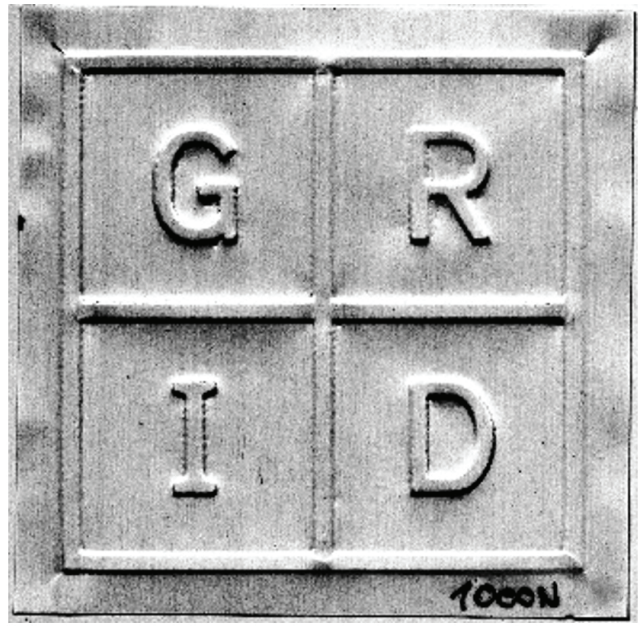

» Figure 8: Appearance of embossed surface on a) OF140 and b) MC130 paper 


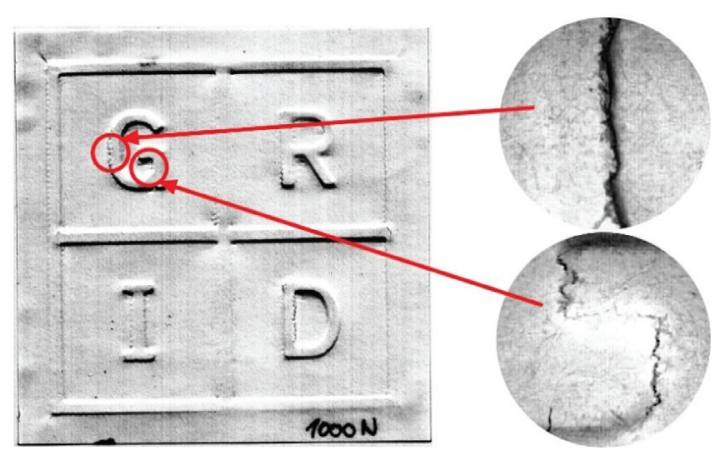

» Figure 9: Appearance of embossed surface on MC9O paper-letter orientation perpendicular to the paper's fibre direction

to the shape of the embossing tool (depth, width and side angle of the embossing element) is preferable.

\section{Conclusions}

Based on the obtained results, it can be concluded that there are valid reasons for introducing fused deposition modelling technology (FDM) in the process of creating paper embossing tools. Usability of this technology was examined through variations of embossing force and characteristics of paper such as paper basis weight, paper structure, surface characteristics and fibre direction. In this research, the 3D printed tool proved its usability under the considerable embossing force. Also, regardless of the structure of the paper, letters are equally well-formed, as well as borderlines. Influence of surface characteristics on the embossed surface is noted at higher basis weights where the greater amount of coating is applied. If the line element of the embossing tool is perpendicular to the paper's fibre direction, with higher embossing forces, cutting or fracture of the paper could appear, which can be overcome with certain optimizations of the embossing tool. This includes changes of height and depth of the elements, the chamfer angle and the gap between male and female parts of the embossing tool. However, these relations should be further explored. Method of producing embossing tools using FDM technology can be used in cases where the embossing elements are not too complex. The reason for this is lack of precision of embossing tools printed using FDM technology. However, if the form is simple, as in this case, results of good quality can easily be achieved. An especially interesting field of application is the personalized production of tools for individual or small-sized embossing in hobby or semi-professional applications, where tools often change, and the volume of the circulation does not require high wear resistance. If we recall that the technique involves using environmentally friendly material which can provide the reduction of negative ecological effect, this method can certainly be recommended.

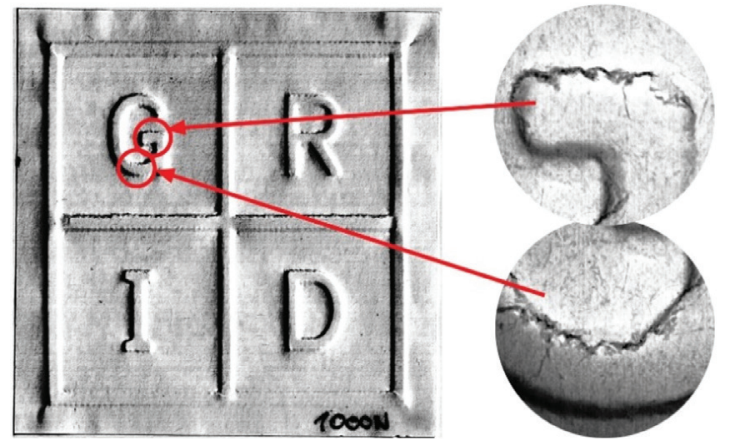

» Figure 10: Appearance of embossed surface on MC9O paper-letter orientation parallel to the paper's fibre direction

\section{Acknowledgements}

The research is supported by the Ministry of Education, Science and Technology Development of the Republic of Serbia, project number: 35027 "Development of software model for scientific and production improvement in graphic industry".

\section{References}

Carrasco F., Pagès P., Gámez-Pérez J., Santana O.O. \& Maspoch M.L. (2010) Processing of poly (lactic acid): Characterization of chemical structure, thermal stability and mechanical properties. Polymer Degradation and Stability. 95(2), 116125. Available from: doi: $10.1016 / \mathrm{j}$.polymdegradstab.2009.11.045 [Accessed 19th September 2017].

Campbell, I., Bourell, D. \& Gibson, I. (2012) Additive manufacturing: rapid prototyping comes of age. Rapid Prototyping Journal. 18(4), 255-258. Available from: doi: 10.1108/13552541211231563 [Accessed 19th September 2017].

Gonnella, R. \& Navetta, C. J. (2010) Comp it up: A studio skills foundation. [Kindle version] Boston, Delmar Cengage Learning.

Haslam, A. (2006) Book design. New York. Laurence King Publishing.

Izdebska, J. \& Thomas, S. (2015) Printing on polymers: Fundamentals and Applications. Philadelphia, Elsevier Science Publishing Co.

Levy, G. N., Schindel, R. \& Kruth, J. P. (2003) Rapid manufacturing and rapid tooling with layer manufacturing (LM) technologies, State of the art and future perspectives. CIRP Annals. 52(2), 589-609. Available from: doi: 10.1016/S00078506(07)60206-6 [Accessed 20th September 2017].

MakerBot. (2016) Material safety data sheet. Available from: https://images.makerbot. com/support/production/SDS-06997_ENA. pdf [Accessed 20th September 2016] 
Nicklievendag. (2017) 3D Printing Filament Guide 2017: ABS vs PLA vs many materials. Available from: http://nicklievendag.com/filament-guide/ [Accessed 20th September 2017].

Ryan, W. E., Conover, T. E. \& Conover, R. (2004) Graphic communications today. 4th ed. Berkeley, Thomson, Delmar Learning.

Sappi (2016) Product selector for printing papers - Europe. Available from: https://www.sappi. $\mathrm{com} /$ product-selector-printing-papers-europe [Accessed 20th September 2017].

Stratasys (2015) Manufacturing Tooling: Find your manufacturing tooling application. Available from: http://www.stratasys.com/solutions/additive-manufacturing/tooling [Accessed 21th September 2017].

Tschaetsch, H. \& Koth, A. (2006) Metal forming practice processes - machines - tools. Berlin. Springer.

Upcraft, S. \& Fletcher, R. (2003) The rapid prototyping technologies. Assembly Automation. 23(4), 318-330. Available from: doi: 10.1108/01445150310698634 [Accessed 21th September 2017].

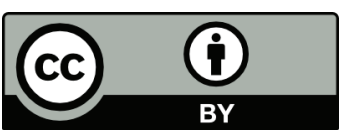

(C) 2017 Authors. Published by the University of Novi Sad, Faculty of Technical Sciences, Department of Graphic Engineering and Design. This article is an open access article distributed under the terms and conditions of the Creative Commons Attribution license 3.0 Serbia (http://creativecommons.org/licenses/by/3.0/rs/). 